\title{
External nasal dilators: definition, background, and current uses
}

\author{
This article was published in the following Dove Press journal: \\ International Journal of General Medicine \\ II November 2014 \\ Number of times this article has been viewed
}

Ricardo Reis Dinardi

Cláudia Ribeiro de Andrade

Cássio da Cunha Ibiapina

Department of Pediatrics, Pediatric Pulmonology Unit, Universidade

Federal de Minas Gerais, Belo

Horizonte, Brazil
Correspondence: Ricardo Reis Dinardi Departamento de Pediatria da Faculdade de Medicina da Universidade Federal de Minas Gerais, Avenida Professor Alfredo Balena, 190/Sala 267 30I30-100 Belo Horizonte, Minas Gerais, Brazil

Tel +55 3l 34099772

Email dinardi06@bol.com.br
Abstract: Our goal was to revise the literature about external nasal dilators (ENDs) as to their definition, history, and current uses. We reviewed journals in the PubMed and MEDLINE databases. The current uses hereby presented and discussed are physical exercise, nasal congestion and sleep, snoring, pregnancy, cancer, and healthy individuals. Numerous studies have shown that ENDs increase the cross-sectional area of the nasal valve, reducing nasal resistance and transnasal inspiratory pressure and stabilizing the lateral nasal vestibule, avoiding its collapse during final inspiration. These effects also facilitate breathing and are beneficial to patients with nasal obstruction. Furthermore, END use is simple, noninvasive, painless, affordable, and bears minimum risk to the user. Most studies have limited sample size and are mainly focused on physical exercise. In conclusion, ENDs seem useful, so further studies involving potential effects on the performance of physical tests and improvements in sleep quality are necessary, especially in children and teenagers.

Keywords: external nasal dilator, nasal valve, nasal congestion, nasal resistance

\section{Definition}

Horizontally fixed to the skin of the nasal dorsum, an external nasal dilator (END) is basically a strip of adhesive tape with two parallel layers of plastic (Figure 1). Going from one nasal wing to the other, and acting as a spring, the goal of such strips is to prevent nasal wings from collapsing and closing during breathing. ${ }^{1}$

An END acts on the nasal valve region, reducing air passage resistance (Figures 2 and 3). Its functioning is rather simple. Each strip has two parallel plastic bars, which smoothly open the nasal passages, improving breathing without medication. Available in different sizes, ENDs are indicated to be used by children, adolescents, and adults.

Located at about one centimeter behind the nostril entrance orifice, the nasal valve is the narrowest passage of the nose, responsible for about $50 \%-60 \%$ of air passage resistance in the respiratory tract. ${ }^{2,3}$ Based on the fact that small changes to its opening would cause significant changes to airflow, many devices were invented in an attempt to broaden the nostrils and prevent them from collapsing during inspiration.

Our goal with this review was to study the history and current uses of ENDs, especially with regard to physical exercise.

\section{Methodology}

We reviewed journals from the PubMed and MEDLINE databases. The search was not restricted to a given time. In order to conduct the search, we used the keywords "external nasal dilator". 


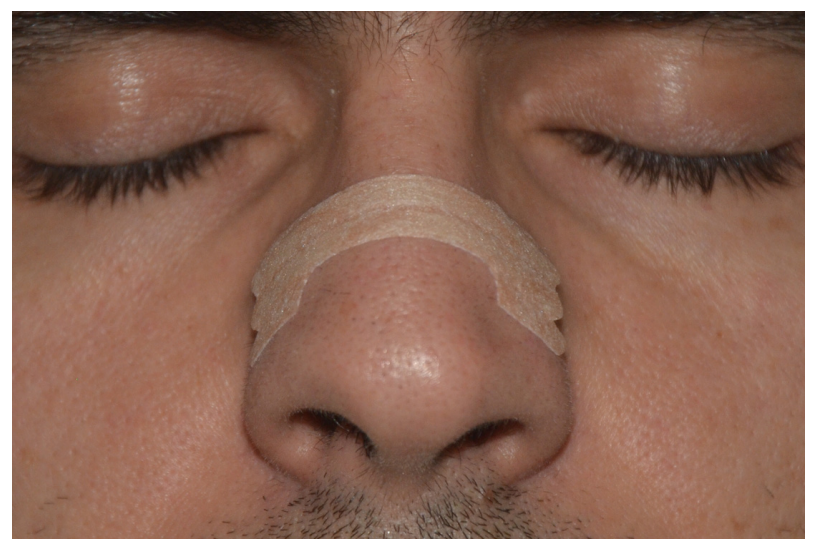

Figure I Front view of the external nasal dilator application site.

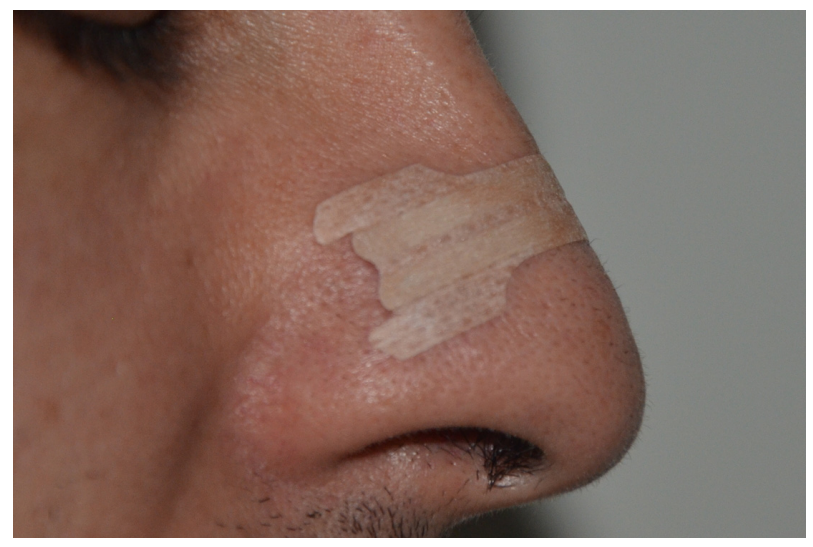

Figure 2 Side view of the external nasal dilator application site.

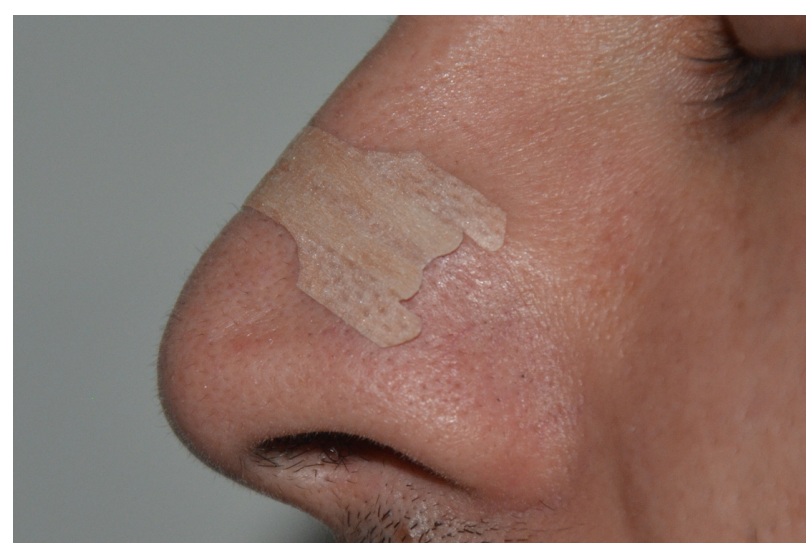

Figure 3 Side view of the external nasal dilator application site.

\section{Background}

Roithmann et $\mathrm{al}^{4}$ and Lancer and Jones ${ }^{5}$ report that in 1905 Francis developed a tool to search for intranasal nasal obstruction in the nasal valve area. In 1986, Lancer and Jones $^{5}$ used rhinomanometry to test this device developed by Francis. There was a significant decrease in nasal resistance in a patient.
Introduced in the 1990s, ENDs became more popular after being used by athletes at the Olympic Games in Atlanta, GA, USA, in $1996 .{ }^{6,7}$ In a randomized study carried out in 1997, Griffin et al $^{2}$ studied 53 athletes aged between 18 and 36 years, tested on a stationary bicycle with and without an END. They used acoustic rhinometry to measure the nasal valve cross-sectional area. The researchers found it to be significantly enlarged $(P<0.001)$.

One year later, a group led by Roithmann et $\mathrm{al}^{4}$ assessed 33 patients with nasal congestion, 28 with nasal septum deviation, and 51 healthy subjects. They used acoustic rhinometry and rhinomanometry to measure the nasal cavity with and without an END, before and after administering nasal decongestant. They used a visual analog scale (VAS) to assess the nasal obstruction sensation. Objective measurements showed that the END reduced nasal resistance in the three groups $(P<0.01)$. The effect was more pronounced in the group with nasal septum deviation $(P<0.001)$. The subjective measurement had a trend toward a significant improvement in those patients with nasal congestion $(P=0.06)$.

An END is efficient to alleviate sleep disorders and snoring caused by reductions in nasal resistance, with benefits caused by a reduction in the nasal breathing effort, increase in nasal ventilation, and delay in oral breathing onset during physical exercise. ${ }^{2,3,8}$ No positive results were found in some studies involving athletic performance. ${ }^{9-11}$

\section{Current uses \\ Physical exercise}

Nespereira and Martínez ${ }^{12}$ reported that without knowing about END benefits, one Spanish marathon runner was world champion in 1997 (Table 1). Many experts associated the victory with his using an END. Considering such a result, the device became popular among high-level athletes. In the same paper, the authors reported that, in 1996, European soccer players were already using ENDs, believing in performance improvement.

According to Ellegård ${ }^{6}$ and Mol and Giannichi, ${ }^{7}$ the use of an END in sports became popular after their use by the Olympic athletes in Atlanta in 1996. Thomas et al ${ }^{13}$ stated in 1998 that such devices were first used in American football players, making up for the mouth guard the athletes had to use, which makes it difficult to breathe through the mouth and, consequently, makes nasal breathing even more important during exercise.

On the other hand, in 2000, Overend et $\mathrm{al}^{14}$ reported that ENDs did not affect athlete performance at maximum or submaximum exercise intensity of adults on treadmills using mouth guards. 

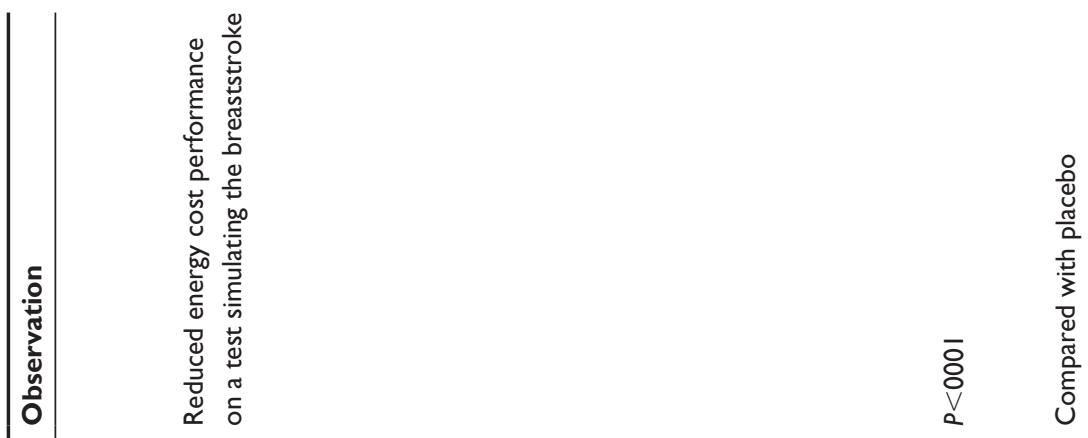

$\frac{\infty}{8}$
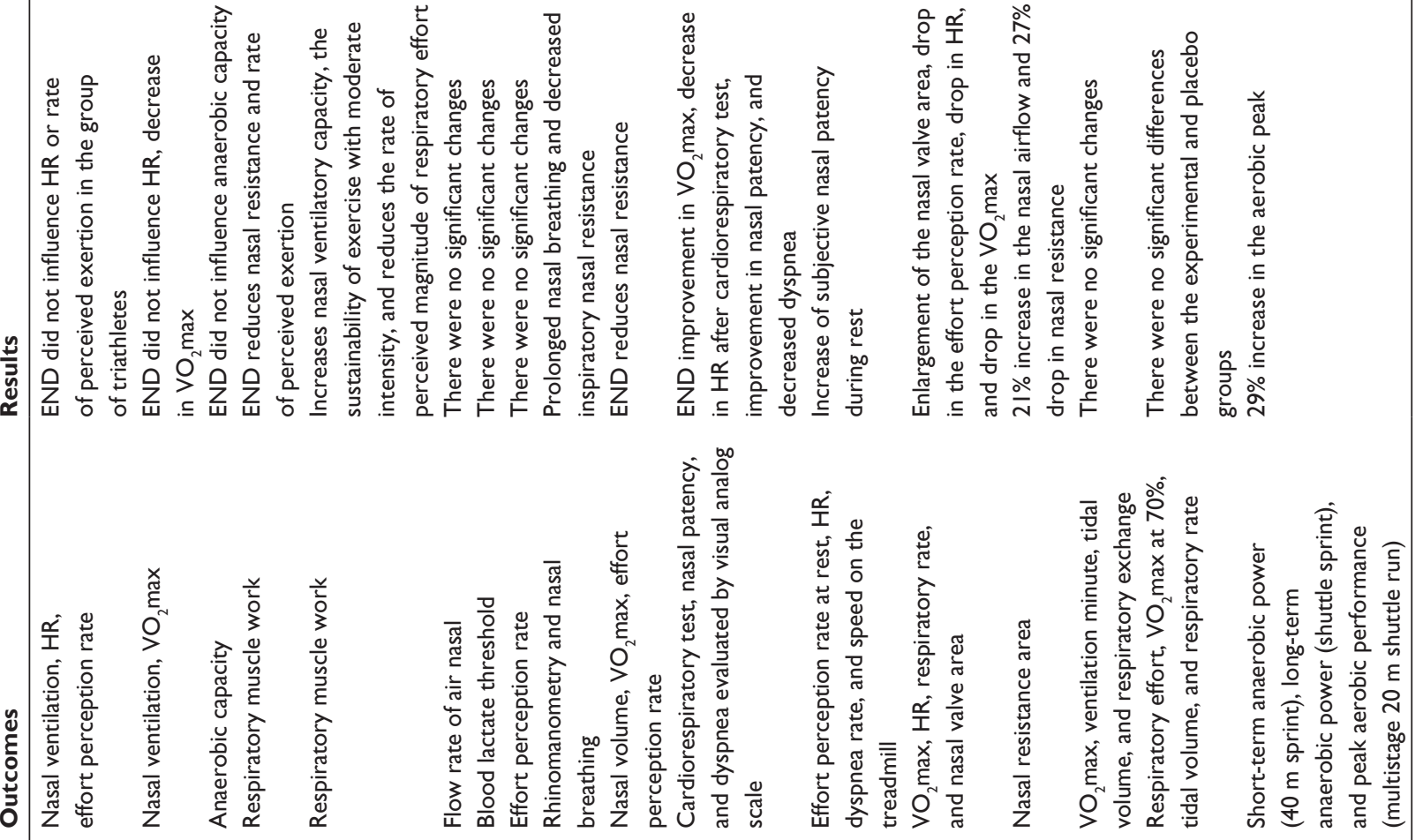

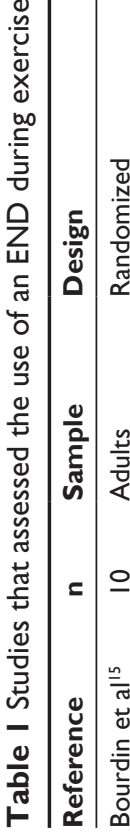
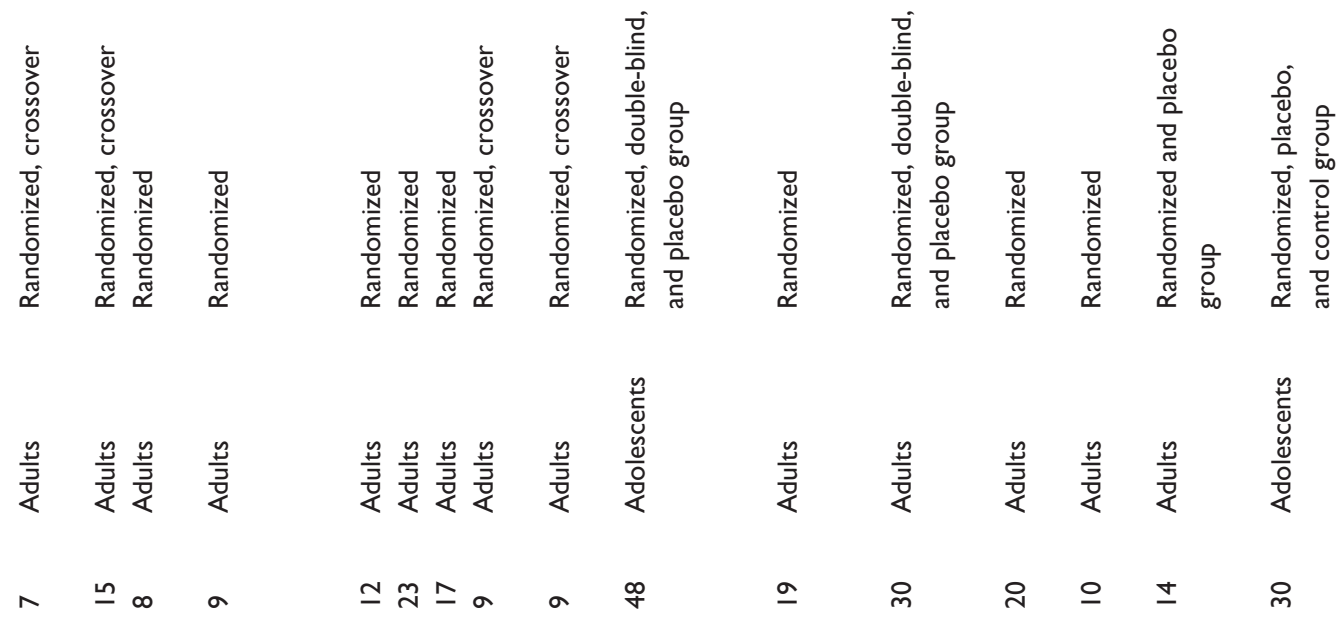

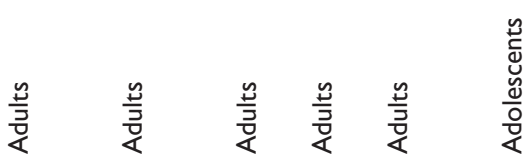

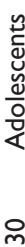

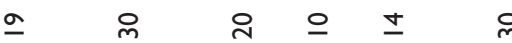

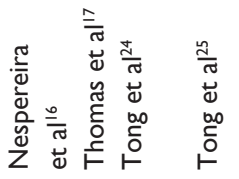

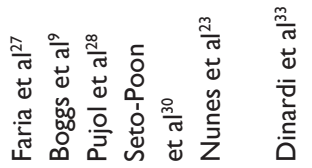

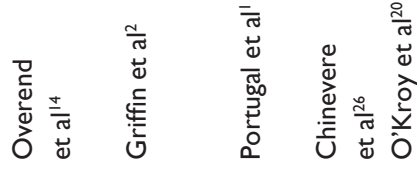

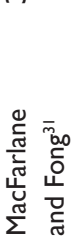


Griffin et al, ${ }^{2}$ in a randomized, double-blind, and controlled study with a placebo group, studied healthy athletes aged between 18 and 33 years. They studied physiological parameters such as oxygen consumption, heart rate, and respiratory rate using a stationary bicycle. Acoustic rhinometry was utilized in order to measure the nasal valve area, and they noticed that, upon rest, with an END, there was a significant increase in the nasal valve area, without differences between ethnicities. During the submaximum exercise protocol, there was a significant reduction in the subjective perception of the effort, heart rate, ventilation, and oxygen consumption when compared with placebo.

On the other hand, in 2002, Bourdin et $\mathrm{al}^{15}$ studied ten triathlon male athletes with a mean age of 23.6 years. The goal of the study was to investigate whether the changes in nasal ventilation could influence the metabolic expenditure and effort perception in a submaximum running test. The subjects were randomized into three situations: normal nasal ventilation, without nasal ventilation (having a clip on the nose), and with an END. Each situation was separated by 10 minute intervals. The protocol was based on 5-minute running sprints at $80 \%$ of the maximum aerobic speed (previously calculated in field situation for each subject). The study indicated that changes in nasal ventilation using the END did not influence heart rate or the perception of effort in the group of triathlon athletes running for 5 minutes at $80 \%$ of the maximum aerobic speed.

In 2004, Nespereira et $\mathrm{al}^{16}$ also observed a significant reduction in oxygen consumption and ventilation $(P<0.05)$ in seven triathlon athletes with a mean age of 22.6 years. The submaximum tests performed at three different intensities were carried out in arm ergometer devices, imitating the movements of the arms when one is swimming the breast stroke. They did not find significant changes in heart rate. The authors concluded that the END reduced energy expenditure in a test simulating the breast stroke. Nonetheless, the magnitude was small and their advantages in such practice seemed to be minimal. ${ }^{16}$

In 1997, Portugal et $\mathrm{al}^{1}$ used acoustic rhinometry and rhinomanometry in order to assess the nasal valve area and resistance of 20 adult male individuals of different ethnic backgrounds. They were analyzed during rest and after 15 minutes of exercise on a stationary bicycle at $70 \%$ of their reserve heart rate, using an END. There was a 21\% airflow improvement in the nasal valve and $27 \%$ nasal resistance reduction in the Caucasian group. The END did not bring significant change in nasal resistance in the group of African descendants. The authors concluded that these differences were probably due to variations in nasal anatomy that happen not only between races but also between individuals of the same race, and it confirms the decongestant effect of exercise provided by means of acoustic rhinometry, until then undocumented in the literature. Thus, there was an improvement in nasal airway using the END, regardless of the decongestant effect of physical exercise.

With the hypothesis that mouth guards would hamper athlete performance, Thomas et $\mathrm{al}^{17}$ decided in 1998 to employ an anaerobic test and observe the effects of an END in athletes who normally use these devices. They used the crossover outline in which ten men and five women aged between 19 and 26 years were randomly selected and analyzed in six tests in four different ways: with mouth guards, without mouth guards, with an END, and without an END (placebo). The results from the study indicated that the use of an END did not change the anaerobic capacity of the athletes who used the mouth guard, analyzed through a 30 -second test. Numerous studies showed that there was no performance improvement with the END. ${ }^{9-11,13,18-23}$

In 2001, Tong et $\mathrm{al}^{24}$ studied END efficacy on the function of the ventilatory muscles during prolonged intermittent exercise. They studied eight untrained adults, and each subject completed 30 series of 20 seconds each on a stationary bicycle, interspersed with 40-second recoveries at the end of each series. The subjects were instructed to pedal as much as possible during the exercise. They studied normal breathing and nostril dilatation with the END. During normal breathing, they observed a reduction in the maximum expiratory pressure before and after exercise $(P<0.05)$, which did not happen with END use. The peak nasal inspiratory flow (PNIF) increased significantly after using the END $(P<0.05)$, suggesting an END-related reduction in nasal resistance. Seven of the eight patients had a higher mean value of initial power in the tests using the END when compared with the controls $(P<0.05)$. Subjective perception of the effort and rates of magnitude perceived in the respiratory effort were also significantly lower with the END $(P<0.05)$. There were no significant changes in ventilatory responses and maximum oxygen consumption $\left(\mathrm{VO}_{2} \mathrm{max}\right)$ in both treatments. The authors concluded that in the sample investigated, using the END during prolonged intermittent induced exercise results in no fatigue of ventilatory muscles and increase in the initial power of the exercise, reducing the perceived magnitude of the respiratory effort.

In the same year, Tong et al studied END efficacy on the sustainability of the exercise in moderate intensity $(75 \%$ $\mathrm{VO}_{2} \max$ ) and some respiratory variables. ${ }^{25}$ They studied nine 
men with a mean age of 20.7 years. The subjects ran on a treadmill and were randomized into oronasal, nasal breathing with an END, and placebo groups. The PNIF increased significantly after using the END $(P<0.05)$ when compared with placebo. During maximum oronasal ventilation for 12 seconds, they observed an increase when compared with the other two conditions. The END was better than placebo under maximum 12-second oronasal ventilation $(P<0.05)$, and the difference between the END and oronasal breathing was not significant $(P>0.05)$. Subjective perception of the effort and rate of magnitude perceived of the respiratory effort all the way to exhaustion did not vary significantly. Nonetheless, the rate of magnitude of the perceived respiratory effort was higher in the placebo group compared with oronasal and END use $(P<0.05)$. There was a drop in maximum static expiratory and inspiratory pressures after the exercise in all respiratory conditions. The authors concluded that END-related nostril dilatation increased the nasal ventilatory capacity, sustaining the exercise with a moderate intensity and reducing the rate of magnitude of the respiratory effort perceived during the exercise. The authors also suggested that those individuals who practice physical exercises at a moderate intensity and who breathe through the nose must use the END, thus preventing exercise-induced asthma. ${ }^{25}$

Since the maximum consumption of oxygen is crucial for athletes, it was measured in numerous studies. In all these studies, ${ }^{2,14,16,20,24-26,28}$ they considered the subjective sensations of the subjects as well as the objective measures of the respiratory capacity.

In 1999, Chinevere et $\mathrm{a}^{26}$ compared the effects of different modes in the respiratory pattern in four healthy men and six women who were submitted to five maximum tests: treadmill breathing through the nose, nose + dilator, mouth, nose + mouth, and nose + mouth + dilator. There were no significant differences between the respiratory modes regarding oxygen consumption, ventilation minute, carbon dioxide production, respiratory exchange ratio, tidal volume, and dead space and in the stages of complete exhaustion on the treadmill. The authors concluded that ENDs may result in limited benefits during exercise when breathing is preferentially nasal.

To test the hypothesis that exercise results in a higher volume and nasal airflow rate, in a randomized study, Faria et $\mathrm{al}^{27}$ carried out numerous static and dynamic nasal breathing maneuvers. Spirometry was carried out in 12 adults aged between 22 and 26 years, under normal nasal breathing and with an END before and after one session of maximum exercise on a treadmill. The results showed that there were no significant differences in the spirometric variables measured with and without the END.

In 2001, O'Kroy et $\mathrm{al}^{20}$ studied END efficacy on the function of the respiratory muscles during exercise to exhaustion. They employed two maximum tests on a stationary bicycle in 14 untrained randomized students with a mean age of $23 \pm 2.7$ years. They assessed the following variables: elastic inspiratory work, resistive inspiratory function, resistive expiratory function, oxygen consumption, ventilation, tidal volume, and respiratory frequency. Using the END, there was no significant difference between the device and the placebo during the exercise.

In one study in which sedentary and trained women were aerobically tested, the authors did not find differences in the levels of blood lactate between using and not using an END in the three groups tested. The data indicate that during moderate- and high-intensity aerobic exercise, an END does not cause improvement in the blood lactate threshold. ${ }^{9}$

In 1998, Pujol et $\mathrm{al}^{28}$ evaluated 17 subjects (ten men and seven women), randomized and analyzed for 20 minutes of running on a treadmill at an intensity of $65 \%$ of their $\mathrm{VO}_{2}$ max. The authors utilized the subjective perception of the central and local overall effort every 5 minutes and did not find differences using an END.

In a sample made up of eight hockey players aged between 18 and 23 years, Deyak et $\mathrm{al}^{29}$ studied the effects of an END on performance and recovery through simulations of game periods. The participants were tested with and without an END on separate days. Acoustic rhinometry was utilized in order to measure the cross-sectional nasal area with and without an END. At the end of each period, they measured heart rate, subjective perception of the effort, and blood lactate sample. They also observed the entire skating time of each period. The blood lactate was lower during skating and resting times when they used the END. The mean skating time was higher with the END when compared with not using the device $(P<0.001)$. Correlation between the difference in nasal cross-sectional area and the skating time using the END was high $(r=0.91 ; P<0.003)$. The authors concluded that the END improved performance and accelerated recovery for the hockey players.

In 1999, Seto-Poon et $\mathrm{al}^{30}$ also found positive results with the use of an END. Healthy adult individuals (four men and five women) were analyzed as to the onset of breathing going from nasal only to mouth-nasal. The authors reported that an END extended nasal breathing during exercise and reduced nasal inspiratory resistance during rest $(P<0.01)$ in seven of the eight subjects assessed by means of rhinomanometry. 
We found only two studies carried out with children in which the researchers assessed END efficacy. Macfarlane and Fong ${ }^{31}$ assessed 30 Chinese male athlete students with a mean age of $15.2 \pm 1.6$ years. The subjects were randomized into six equal groups and analyzed under three situations: END, placebo, and control. They used the modified Borg scale (Wilson and Jones ${ }^{32}$ ) to assess the respiratory effort perception and employed three maximum running tests: 1) short-term anaerobic power (40 m sprint), 2) long-term anaerobic power (shuttle sprint), and 3) peak aerobic performance (multistage $20 \mathrm{~m}$ shuttle run).

There were no significant differences in the anaerobic tests in all the situations. The aerobic performance, when compared with the placebo, showed that the END provided a significant increase $(P=0.018)$ of $2.9 \%$. In long-term aerobic power, the END significantly reduced $(P=0.043)$ the perceived respiratory effort rate when compared with placebo and control $(P=0.010)$. Concerning aerobic performance, there was also a significant reduction in the perceived respiratory effort rate when compared with controls $(P=0.016)$ and the placebo $(P=0.048)$. The authors concluded that an END may significantly reduce respiratory effort and improve peak aerobic performance during field tests involving maximum running.

Dinardi et $\mathrm{al}^{33}$ evaluated the effectiveness of ENDs (Figure 4) in healthy adolescent athletes and compared experimental and placebo groups and reported an improvement in $\mathrm{VO}_{2} \max \left(53.0 \pm 4.2 \mathrm{~mL} / \mathrm{kg} \cdot \mathrm{min}^{-1}\right.$ and $51.2 \pm 5.5 \mathrm{~mL} / \mathrm{kg} \cdot \mathrm{min}^{-1}$, respectively) $(P<0.05)$; decrease in heart rate after cardiorespiratory test (experimental $=159 \mathrm{bpm}$ and placebo $=168$ bpm) $(P=0.015)$; improvement in nasal patency measured by the PNIF (123 $\pm 38 \mathrm{~L} / \mathrm{min}$ and $117 \pm 35 \mathrm{~L} / \mathrm{min}$, respectively); and decreased dyspnea evaluated by VAS $(P<0.05)$.

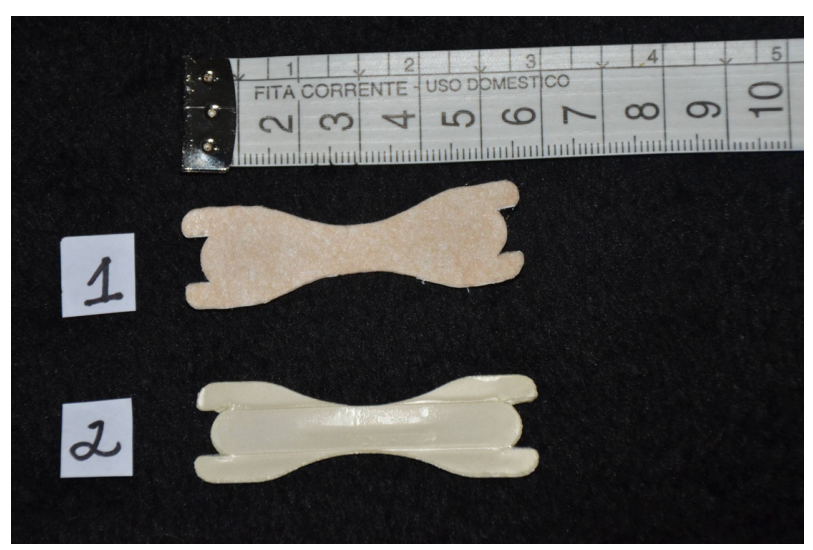

Figure 4 Placebo external nasal dilator strip (I) and experimental external nasal dilator strip (2) used by Dinardi et al. ${ }^{33}$
More recently, Nunes et al, ${ }^{23}$ in a randomized, crossover study, investigated nine healthy men submitted to three sessions of submaximum aerobic exercise $\left(60 \% \mathrm{VO}_{2}\right.$ max during 1 hour) with an END, a placebo, and without the device. There was a significant increase in nasal volume measured by acoustic rhinometry $(P<0.05)$ when compared with placebo. There were no differences in heart rate, $\mathrm{VO}_{2} \max$, ventilation, and rate of effort perception between the three situations analyzed. The authors concluded that the END did not affect physiological parameters during the submaximum aerobic exercise and that the reduction in nasal resistance caused by the END must be of little functional importance to most people during exercise.

\section{Nasal congestion and sleep}

The relationship between sleep disorders, snoring, and nasal congestion has been extensively studied, and an END seems to be a means of prevention and treatment (Table 2). ${ }^{34-39}$ Many measures were used to study END efficacy. Some evaluated airflow direction, others evaluated nostril area, and others airflow resistance.

Raudenbush ${ }^{40}$ used a questionnaire to select 30 healthy individuals who complained of nasal obstruction during sleep. The goal was to compare the efficacy of two different nasal dilators, an internal one (Max-Air Nose Cones; Sanostec Corp, Beverly Farms, MA, USA) and an external one (Breathe Right ${ }^{\circledR}$ nasal strip; GlaxoSmithKline, Brentford, Middlesex, UK) on nasal patency assessed by PNIF. The subjects performed the Clement Clarke In-Check Flow Meter maneuver as control with the internal and external dilators. They considered the highest PNIF value obtained after three attempts. The control values were significantly lower (mean $[\mathrm{M}]=66.07 \mathrm{~L} / \mathrm{min}$; standard deviation $[\mathrm{SD}]=22.56 \mathrm{~L} / \mathrm{min}$ ) when compared with both the internal $(\mathrm{M}=138.73 \mathrm{~L} / \mathrm{min} ; \mathrm{SD}=30.30 \mathrm{~L} / \mathrm{min})$ and external dilators $(\mathrm{M}=102.17 \mathrm{~L} / \mathrm{min} ; \mathrm{SD}=26.04 \mathrm{~L} / \mathrm{min})$. The highlight was the internal dilator, where there was an increase of $73 \mathrm{~L} / \mathrm{min}$ in inspiratory airflow, or $110 \%$ improvement compared with the control situation. In this study, the Max-Air Nose Cones were significantly better than the END Breathe Right nasal strip in improvements in PNIF. ${ }^{40}$

Roithmann et $\mathrm{al}^{41}$ studied the effects of ENDs on the crosssectional area of the nasal valve in healthy individuals and in those with nasal obstruction after rhinoplasty. They used the VAS with the END after decongestant use and control. The scale was developed with two extremes: "my nose is totally free" $(0 \mathrm{~mm})$ and "my nose is totally blocked" (100 $\mathrm{mm})$. In order to measure the cross-sectional area, volume, 


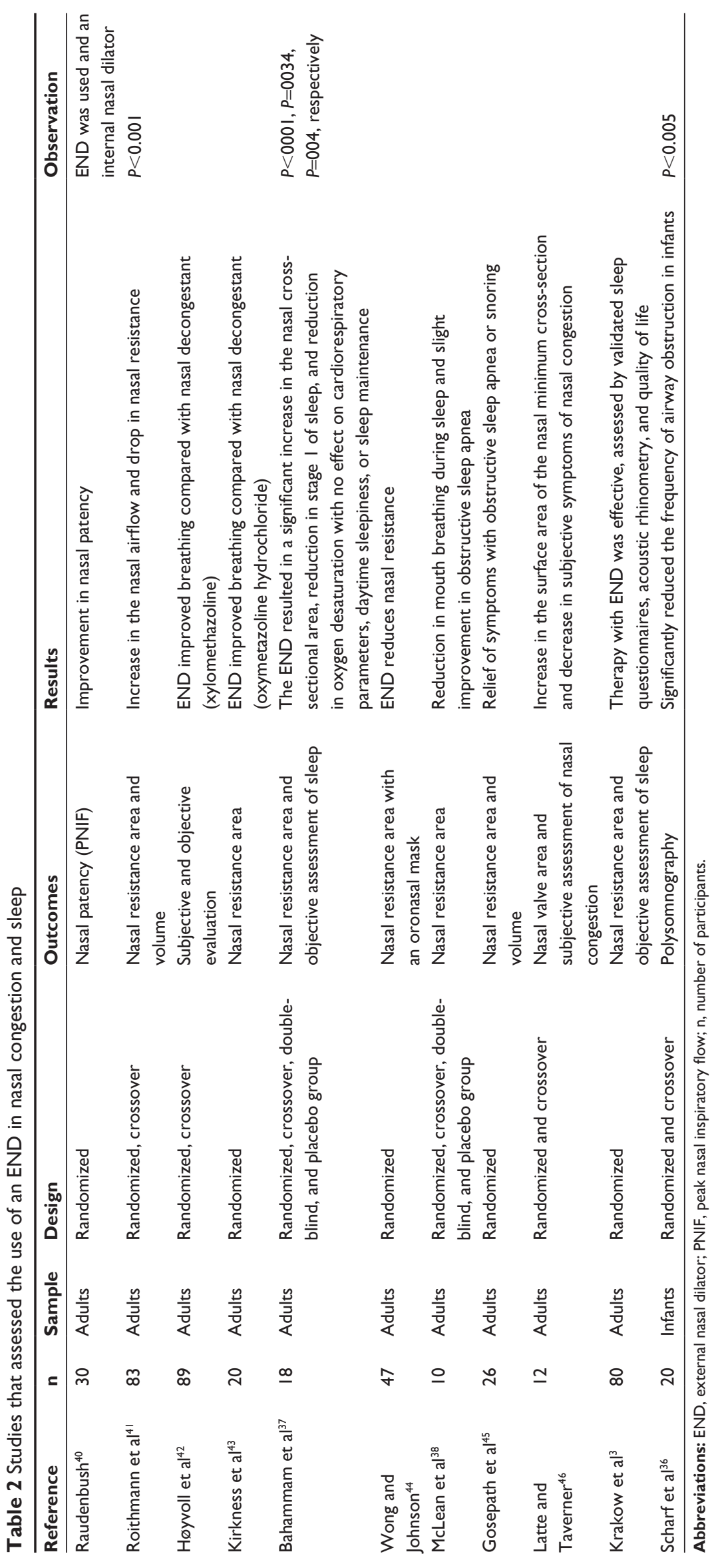


and nasal resistance, they used acoustic rhinometry. In those individuals with healthy nasal cavities, they observed a significant increase in the nasal valve cross-sectional area, for both the proximal and the distal portions of the nostril. In the postrhinoplasty group with nasal congestion, the END significantly increased $(P<0.001)$ the nasal valve cross-sectional area. The authors concluded that an END enlarges the nasal cross-sectional area in individuals with nasal obstruction, causing an immediate improvement in breathing. ${ }^{41}$

Høyvoll et $\mathrm{al}^{42}$ compared an END with a nasal decongestant (xylomethazoline) in 89 individuals with nasal congestion. They used objective and subjective assessments. The study showed that the END enhanced nasal breathing when compared with the decongestant. The authors recommended ENDs as an alternative treatment instead of using nasal decongestants, especially in those with nasal congestion in the anterior valve area.

In 2000, Kirkness et $\mathrm{al}^{43}$ also included a nasal decongestant (oxymetazoline hydrochloride) in their study before and after using an END, without the END and with a placebo. They evaluated nasal resistance of 20 healthy adults. According to the authors, this was the first paper to assess an END's effect on inspiratory nasal resistance and transnasal inspiratory pressure during hyperpnea. They also suggested the concept of having individuals who respond and those who do not respond to an END, noticed that the device influenced the dynamic airflow through the nasal valve dilation and stabilization of the nasal lateral vestibule, and developed the hypothesis that it can be more effective in individuals with high resistance to airflow at rest.

Designed to be a double-blind and randomized crossover study (treatment and placebo), in 1999, Bahammam et $\mathrm{al}^{37}$ studied 18 adult patients with upper airway resistance syndrome. Each patient was analyzed during 2 nights with a 1-week interval, using polysomnography. The END resulted in a significant increase in the nasal cross-sectional area $(P<0.001)$, reduction in stage 1 of sleep $(P=0.034)$, and reduction in oxygen desaturation $(P=0.04)$, with no effect on cardiorespiratory parameters, daytime sleepiness, or sleep maintenance.

With the goal of measuring airflow resistance with an oronasal mask, Wong and Johnson ${ }^{44}$ tested 47 adults with symptoms of nasal congestion, asthma, allergy, and snoring. The END reduced nasal resistance in an average of 0.5 $\mathrm{cm} \mathrm{H}_{2} \mathrm{O} /$ liters per second. The effect was the same during inspiration and expiration. The same authors reported that they were unable to comment on the clinical relevance of the resistance reduction with the END.
In a randomized and controlled study with placebo and treatment (topical decongestant and END), crossover style, Mclean et $\mathrm{al}^{38}$ studied ten adult patients with normal retroglossal air passage, nasal obstruction, and obstructive sleep apnea. They investigated the effects of treatment on nasal resistance, oral breathing during sleep, and significant sleep apnea. The authors aimed at clarifying the relationship between nasal obstruction and obstructive sleep apnea with oral breathing. They noticed that END use alleviated nasal obstruction in patients with normal retroglossal air passage, causing a significant reduction in oral breathing during sleep and mild improvements in the obstructive sleep apnea. They concluded that treating nasal obstruction has a direct impact on normalizing nasal breathing during sleep, and little or no difference in obstructive sleep apnea.

Gosepath et $\mathrm{al}^{45}$ analyzed the effects of an END in 26 adults with obstructive sleep apnea and/or snoring. They used topical decongestants (naphazolin) before and after polysomnography, rhinomanometry, and acoustic rhinometry. Demographic data, rhinoscopy, and clinical studies in pharyngeal obstruction were also utilized to identify the correlation of END-positive effects with the respiratory disorder indices. They concluded that there had been a significant symptom reduction in individuals with obstructive sleep apnea or snoring. They suggested that the positive effect could be better, according to the data obtained in this sample, following criteria such as inferior turbinate hypertrophy or hyperplasia, septum deviation, allergic rhinitis, no pharyngeal obstruction, or age $<55$ years.

In 2005, Latte and Taverner ${ }^{46}$ studied two different types of ENDs. They investigated whether there had been an influence of nasal valve size and congestion symptoms in 12 healthy individuals aged between 26 and 56 years. The study was randomized and with crossover outline, and each subject was assessed with an END: Breathe Right, side strip nasal dilators, and placebo. In order to compare the effects of END and placebo, they used acoustic rhinometry to measure total volume and minimum nostril cross-sectional area. For the subjective analysis of the nasal congestion, they used VAS and ordinal scales. They noticed a significant increase in the minimum nasal cross-sectional area using the two ENDs compared with placebo $(P=0.004)$, and subjective reduction of the nasal congestion using the VAS compared with placebo $(P=0.012)$ and the ordinal scale compared with placebo $(P=0.004)$.

In 2006, Krakow et $\mathrm{al}^{3}$ selected 80 adult individuals with insomnia associated with difficult breathing during sleep. They were randomized for treatment with an END $(n=42)$ 
and control $(n=38)$ and assessed for 4 weeks. Treatment with the END was efficient, assessed by validated sleep questionnaires, rhinometry, and quality of life.

In a study carried out by Scharf et $\mathrm{al}^{36}$ in 1996 , which aimed at assessing END efficacy in reducing sleep disorder indices, they studied 20 infants using polysomnography. Of these, 15 were healthy, with a mean value \pm SD of $85.7 \pm 21$ days, and five with nasal congestion with a mean \pm of $78.2 \pm 19$ days. They used the crossover outline in which all the subjects were randomized and assessed during sleep with and without the END. The data were based on follow-up 2 hours of sleep during the day. The authors concluded that the END significantly reduced $(P<0.005)$ respiratory obstruction frequency in infants.

\section{Snoring}

ENDs have been proposed to reduce or eliminate snoring and improve nasal breathing. ${ }^{47-50}$ The first randomized study to show snoring reduction using an END was carried out with 12 nonobese individuals with a mean age of $43 \pm 2.8$ years, diagnosed with chronic rhinitis and high nasal resistance (Table 3). ${ }^{49}$ In that study, snoring frequency was significantly lower with the END compared with placebo $(P=0.016)$. The authors concluded that an END may be one alternative to treat snoring in individuals with chronic rhinitis and possibly with other causes that compromise nasal breathing.

Scharf et al ${ }^{51}$ assessed ten men and ten women considered "mild snorers" aged between 22 and 54 years for 2 weeks. The subjective assessment instrument was the Stanford Sleepiness Scale answered during breakfast, lunch, and dinner and filled out by their bed partners after 1 night of sleep. The main result of this study was a snoring improvement in $75 \%$ of the subjects. In addition, they also observed less daytime sleepiness, less nighttime waking, and better sleep quality.

In 2001, Djupesland et al ${ }^{52}$ studied 18 adult individuals considered "heavy snorers" without obstructive sleep apnea syndrome. They were randomized with a crossover outlining and assessed subjectively/objectively as to END effects on nasal cavity size, sleep quality, and snoring. Six individuals previously submitted to unsuccessful surgery to treat snoring and high nasal obstruction were analyzed and compared with the rest of the sample. Nasal patency, sleep quality, dry mouth in the morning, and snoring improved significantly $(P<0.01)$ and were assessed through a VAS. There was a significant $(P<0.001)$ increase in the minimum cross-sectional area and in nasal volume with the END when compared with the placebo, both at dusk and before the polysomnography the following morning. There were 
Table 4 Studies that assessed the use of an END in pregnancy and cancer

\begin{tabular}{|c|c|c|c|c|c|c|}
\hline Reference & $\mathbf{n}$ & Sample & Design & Outcomes & Results & Observation \\
\hline Turnbull et a $\left.\right|^{35}$ & 24 & Adults & $\begin{array}{l}\text { Randomized and } \\
\text { placebo group }\end{array}$ & Subjective assessment & $\begin{array}{l}\text { Subjective improvement in quality of } \\
\text { breathing in the group using the END }\end{array}$ & \\
\hline Sadan et $\mathrm{a}^{54}$ & 150 & Adults & $\begin{array}{l}\text { Randomized and } \\
\text { placebo group }\end{array}$ & Subjective assessment & $\begin{array}{l}\text { High satisfaction rate in the group } \\
\text { using the END }\end{array}$ & $P<0.000 I$ \\
\hline $\begin{array}{l}\text { Neuenschwander } \\
\text { et al }{ }^{55}\end{array}$ & 9 & Adults & Randomized & $\begin{array}{l}\text { Subjective assessment } \\
\text { (Likert scale) }\end{array}$ & $\begin{array}{l}\text { Good tolerability and there is no } \\
\text { contraindication in patients with cancer }\end{array}$ & \\
\hline
\end{tabular}

Abbreviation: END, external nasal dilator; $n$, number of participants.

no significant changes in snoring characteristics and sleep quality. In a subgroup of individuals ( $\mathrm{n}=6$ ), nasal dilatation with the END provided a significant improvement in oxygen saturation during sleep and decreased the percentage of sleep with saturation $<95 \%$ (from $49.9 \%$ to $4.9 \%)(P<0.05)$. The authors concluded that the positive results using an END benefit only individuals with significant nocturnal nasal obstruction.

In 1997, Ulfberg and Fenton ${ }^{48}$ analyzed the effects of END on snoring, dry mouth, and badly slept nights in 18 women and 17 adult men without apnea. They asked the companions of each subject about snoring intensity on a 1-5 scale (5 being the highest snoring intensity). The subject answered questions about the dry mouth feeling on a 1-5-scale (5 the driest) and answered a validated questionnaire about quality of sleep (Epworth Sleepiness Scale ${ }^{53}$ ). These three instruments were administered immediately before and 2 weeks after the study started. The authors concluded that there was a significant improvement in the three variables analyzed, namely $P<0.001, P=0.025$, and $P=0.001$, respectively, and indicated ENDs for individuals with these symptoms.

In another study, the authors found different results with the END when individuals without apnea who snore were analyzed during different sleep stages using polysomnography. ${ }^{47}$ They selected ten individuals of whom five had nasal valve anomalies. The authors did not find a positive effect on snoring and sleep parameters in individuals without apnea with or without a nasal valve.

\section{Pregnancy}

Difficult breathing caused by nasal obstruction is common during the second half of pregnancy. This problem is more frequent during the night. ${ }^{35}$

In a study carried out by Turnbull et al, ${ }^{35} 24$ women between the 16th and 39th weeks of gestation with nasal congestion were randomized into two groups: one of them used placebo, and the other an END (Table 4). The subjects were assessed during 3 nights. One questionnaire with ten questions was used to assess breathing, ease of sleep, continuity, and sleep depth. There was a subjective improvement in the breathing quality of the group that used the END.

In 2005 , Sadan et $\mathrm{al}^{54}$ assessed 150 pregnant women and reported a high satisfaction rate in the group that used the END when compared with the placebo group $(P<0.0001)$.

In the present review, we found only two papers involving pregnant women. This confirms the need for future studies that should, preferably, incorporate the design of a controlled and randomized study with a proper sample size and include independent and blind assessments of ENDs in pregnant women.

\section{Cancer}

Considering the hypothesis that a reduction in respiratory effort could bring benefits to cancer patients with dyspnea, Neuenschwander et $\mathrm{al}^{55}$ carried out a pilot study with nine adult patients using an END (Table 4). Patients were assessed at 4, 8, and 12 hours after employing the END as to the dyspnea perceived through the Linkert scale. One patient reported having had a good improvement in her dyspnea, three reported moderate improvement, two said they had a small improvement, and three reported they had no improvement at all. As far as tolerability is concerned, they employed the same scale and found four patients with good tolerability and four with moderate. One patient did not feel well and removed the END. Seven patients decided to continue using the END. The authors suggest that patients with cancer should use the device because it is well tolerated and has no contraindications.

\section{Healthy individuals or other applications for an END}

Studies have shown that an END increases the cross-sectional area of the nasal valve, reducing nasal resistance in up to $27 \%$ and causing a subjective improvement in the nasal patency of healthy individuals (Table 5). 1,2,457-59

Healthy individuals, 33 men and 12 women, with ages varying between 26 and 82 years, had their pulse oxymetry 


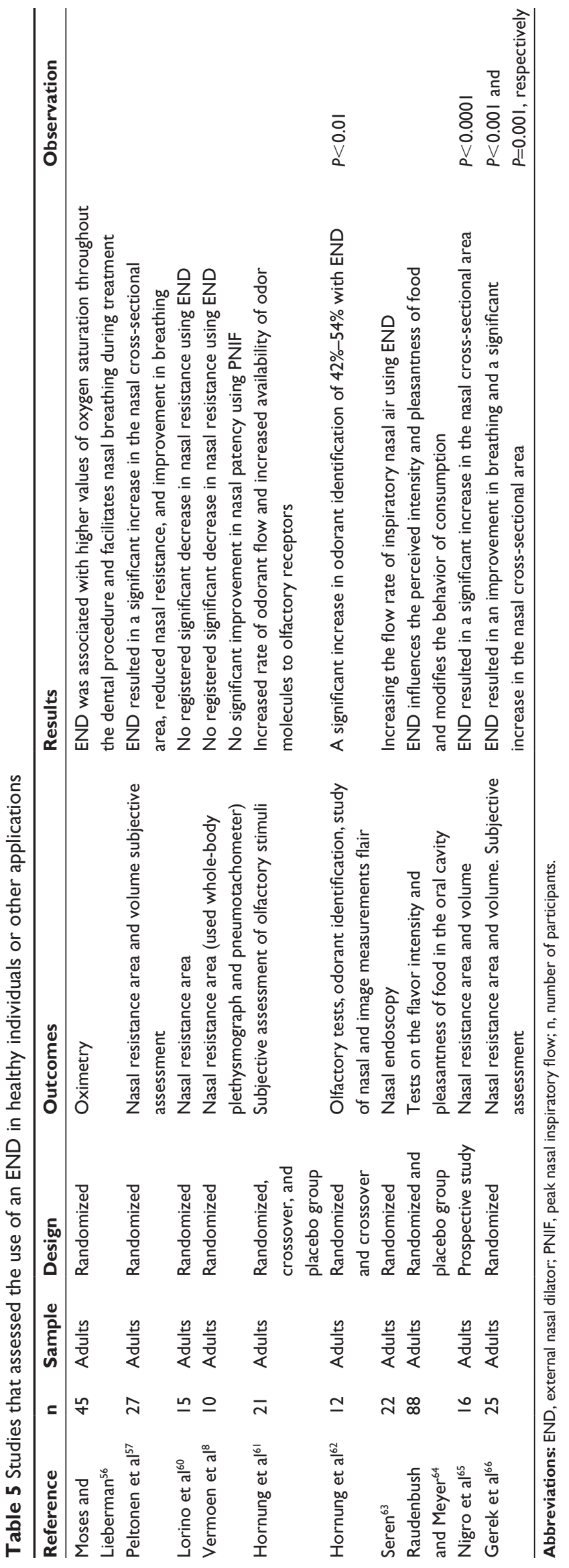

assessed during a dental procedure. ${ }^{56}$ Patients with initial oxygen saturation of $\leq 95 \%$ were selected $(n=15)$ to be treated with an END. The authors concluded that END use is associated with higher oxygen saturation values during the dental procedure. On the other hand, there was a drop in the saturation of those $(n=30)$ who did not use the END during the dental procedure. Another important conclusion is that an END facilitates nasal breathing in dental procedures.

Peltonen et $\mathrm{al}^{57}$ investigated two devices that, theoretically, increased nasal airflow. One of the devices was the END (Breathe Right) and the other one an internal nasal dilator $\left(\right.$ Nozovent $\left.^{\mathbb{}}\right)$. The goal was to assess nasal anatomy and the subjective respiratory sensation using rhinomanometry and acoustic rhinometry in 15 men and 12 women with a mean age of 27 years. Both devices increased significantly the minimum cross-sectional nasal area and reduced nasal resistance. All the volunteers reported improvements in breathing.

In a similar situation, in 1998, Lorino et al ${ }^{60}$ compared the effect of three treatments with the goal of reducing nasal resistance in 15 healthy individuals aged between 18 and 45 years. The treatments were based on normal breathing, use of an END (Respir ${ }^{\circledR}$; Kentia Diffusion; Boulogne, France), an internal nasal dilator (Nozovent; Prevancure; Ste Pouret, Paris, France), and $0.05 \%$ of nasal decongestant (tymazoline hydrochloride; Pernazene; Synthelabo; le Plessis-Robinson, France). The nasal resistance was assessed by means of posterior rhinometry. We did not find a significant reduction in nasal resistance using the END (Respir+).

Similarly, in 1998, Vermoen et $\mathrm{al}^{8}$ did not find significant differences in nasal resistance with and without an END. The goal of the study was to check the effect of an END by assessing nasal resistance during normal breathing and forced inspiratory and expiratory flow volumes with and without an END in ten healthy adults. They used full body plethysmography and a pneumotachometer, respectively. Nonetheless, they found significantly higher values in the forced expiratory volume in a second with the END, compared with not using the END. The mean improvement was $0.26 \mathrm{~L}$ ( $\mathrm{SD}=0.36, P=0.045$ ). There was no significant improvement in the PNIF; therefore, there was no increase in nasal patency during normal breathing. The authors concluded that an END improves forced nasal inspiration, preventing the collapse of the external nostrils under negative nasal pressure.

Hornung et $\mathrm{a}^{61}$ assessed olfactory stimuli with and without an END in healthy adult individuals. The authors carried out two experiments. In the first, ten subjects were randomized into two groups. In the first group, the subjects 
were assessed through a series of smells with and without the END. After 1 hour, the evaluation order was inverted in the second group. The second experiment was carried out in order to establish the reproducibility and specificity of the results achieved in the first experiment. The second experiment was based on assessing the smell intensity of eleven subjects broken down into two groups. In group 1, the subjects were assessed with and without the END. In group 2, the subjects were assessed with and without a placebo END. The END was associated with higher smell intensity scores in nine of the ten individuals in the first experiment. The results observed in the second experiment were similar. The authors argued that a reduction in nasal resistance caused by an END may increase the rate of odor flow and an increase in the availability of odor molecules for the olfactory receptors.

Four years later, Hornung et $\mathrm{al}^{62}$ studied the effects of an END on smell capability. There were 12 healthy adults participating in the study. They carried out olfactory tests, odor identification, nasal image studies, and smell measuring. There was a significant increase in smell identification, from $42 \%$ to $54 \%$ with the END $(P<0.01){ }^{62}$

More recently, Seren ${ }^{63}$ studied the effects of an END on the inspiratory nasal flow of 22 healthy individuals. They used nasal endoscopy in both nostrils with the patient at rest. They introduced a microphone into the nasal cavity of the subjects, and the sound produced by the nasal flow was analyzed by software called "Odiosoft-Rhino". The parameters utilized to characterize the intensity and frequency of nasal sounds were defined as of low, medium, and high frequency. The author reported a $31 \%$ reduction (from 26.8 to $18.6 \mathrm{~dB}$ ) in sound intensity at high frequency as a result of END use, and associated this phenomenon with an increase in the nasal inspiratory airflow rate.

In 2001, Raudenbush and Meyer ${ }^{64}$ studied END effects on the intensity of taste and palatability of food in the oral cavity of 88 individuals with a mean age of 19 years (47 men and 41 women). The subjects were randomized and treated with the original END and placebo. They chose ten types of food with different tastes and were randomized as to the order of each subject. The subjects found the food was less agreeable when using the END when compared with placebo (respectively, $\mathrm{M}=5.27, \mathrm{SD}=3.24$, and $\mathrm{M}=6.01$, $\mathrm{SD}=3.36$ ). As to flavor intensity, the subjects found it to be more intense using the END when compared with placebo (respectively, $\mathrm{M}=7.25, \mathrm{SD}=2.04$, and $\mathrm{M}=5.66, \mathrm{SD}=2.14$ ). As to the consumption stimulation, when the subjects used the END, they consumed less food $(\mathrm{M}=1.41 \mathrm{~g}, \mathrm{SD}=1.29)$

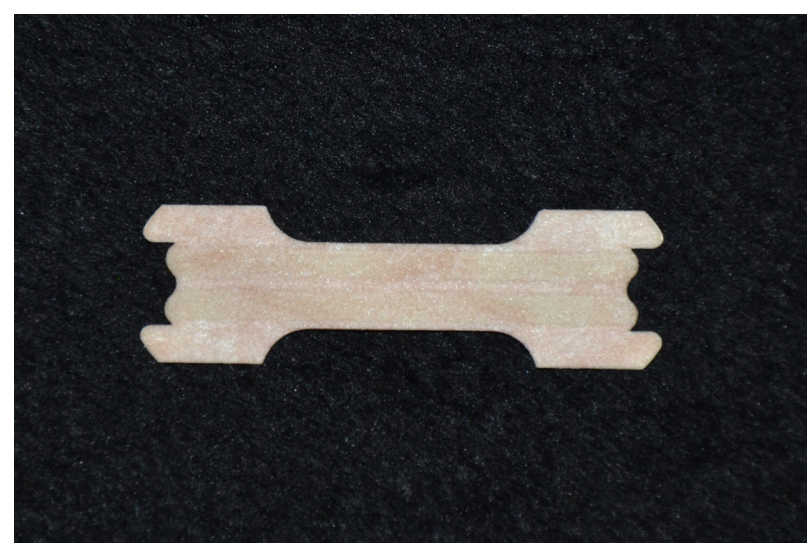

Figure 5 External nasal dilator (Breathe Right, GlaxoSmithKline Brazil Ltd., Rio de Janeiro, Brazil).

when compared with placebo $(\mathrm{M}=2.32 \mathrm{~g}, \mathrm{SD}=2.70)$. The findings of this paper suggest that an END influences the perceived intensity and the agreeability of the food, and it changes food consumption behavior.

In 2011 , Nigro et $\mathrm{al}^{65}$ led a prospective study in which they assessed 32 nasal cavities from healthy adults. The study's goal was to assess the anatomical correlation of the two regions of the nose. They used acoustic rhinometry to assess the following conditions: 1) basal condition; 2) with ENDs (Breathe Right, GlaxoSmithKline Brazil Ltd., Rio de Janeiro, Brazil; Figure 5) placed above the upper lateral cartilage; 3) 20 minutes after decongestion with $0.05 \%$ oxymetazoline chloride applied as an aerosol spray (two times); and 4) after decongestion with ENDs. The authors classified as crosssectional area 1 (CSA-1) the region called "internal ostium" and the cross-sectional area 2 (CSA-2) the "isthmus nasi" region. There was an increase in the CSA-1 (from 0.68 to $0.74 \mathrm{~cm}^{2} ; P<0.0001$ ) and CSA-2 (from 0.52 to $0.77 \mathrm{~cm}^{2}$; $P<0.0001)$ when the normal situation was compared with the END. There was no statistically significant variation in CSA-1 after decongestant administration. However, there was a significant increase in CSA-2 after END use. Therefore, the results suggest that they may contribute to establish an anatomical correlation between the two regions studied.

Even finding statistically significant results using the VAS to improve breathing and acoustic rhinometry, where they assessed the minimum nasal cross-sectional area $(P<0.001$; $P=0.001$, respectively), Gerek et al ${ }^{66}$ in 2012 did not find a relationship between the nasal valve and nasal voice in 25 healthy adults. They used acoustic rhinometry and nasometry with and without an END. The authors concluded that the changes caused by the END to the nasal valve did not change the nasal characteristic of the voice. 


\section{Conclusion}

Numerous studies have shown that an END increases the nasal valve cross-sectional area, reduces nasal resistance, reduces inspiratory transnasal pressure, and stabilizes the lateral nasal vestibule wall, thus avoiding its collapse during final inspiration. These effects facilitate nasal breathing and are beneficial for patients with nasal congestion, regardless of cause. Notwithstanding, most studies are made up of small samples. We stress that ENDs are simple, noninvasive, painless, affordable, and with minimum risk for the user.

We found only three papers carried out with children in which the researchers analyzed END efficacy, only two of them during physical exercise.

We conclude that we need further studies involving potential effects on physical activities and improvements in sleep quality, especially in children and adolescents.

\section{Acknowledgment}

We would like to thank the biologist Luísa Penido Avelar for their valuable contribution.

\section{Disclosure}

The authors report no conflicts of interest in this work.

\section{References}

1. Portugal LG, Mehta RH, Smith BE, Sabnani JB, Matava MJ. Objective assessment of the breathe-right device during exercise in adult males. Am J Rhinol. 1997;11(5):393-397.

2. Griffin JW, Hunter G, Ferguson D, Sillers MJ. Physiologic effects of an external nasal dilator. Laryngoscope. 1997;107(9):1235-1238.

3. Krakow B, Melendrez D, Sisley B, et al. Nasal dilator strip therapy for chronic sleep-maintenance insomnia and symptoms of sleep-disordered breathing: a randomized controlled trial. Sleep Breath. 2006;10: 16-28.

4. Roithmann R, Chapnik J, Cole P, Szalai J, Zamel N. Role of the external nasal dilator in the management of nasal obstruction. Laryngoscope. 1998;108(5):712-715.

5. Lancer JM, Jones AS. The Francis alae nasi prop and nasal resistance to airflow. J Laryngol Otol. 1986;100(5):539-541.

6. Ellegård E. Mechanical nasal alar dilators. Rhinology. 2006;44(4): 239-248

7. Mol RF, Giannichi RS. The influence of the nasal dilator in maximal oxygen uptake. R Min Educ Fis. 1998;6(2):46-58.

8. Vermoen CJ, Verbraak AF, Bogaard JM. Effect of a nasal dilatator on nasal patency during normal and forced nasal breathing. Int J Sports Med. 1998;19(2):109-113.

9. Boggs GW, Ward JR, Stavrianeas S. The external nasal dilator: style over function? J Strength Cond Res. 2008;22(1):269-275.

10. Baker KM, Behm DG. The ineffectiveness of nasal dilator strips under aerobic exercise and recovery conditions. J Strength Cond Res. 1999;13(3):206-209.

11. O'Kroy JA. Oxygen uptake and ventilatory effects of an external nasal dilator during ergometry. Med Sci Sports Exerc. 2000;32(8) 1491-1495.

12. Nespereira AB, Martínez IP. Influencia de las tiritas nasales sobre el rendimiento deportivo. Apunts: Educación Física y Deportes. 2003;71:40-47.
13. Thomas DQ, Larson BM, Rahija MR, McCaw ST. Nasal strips do not affect cardiorespiratory measures during recovery from anaerobic exercise. J Strength Cond Res. 2001;15(3):341-343.

14. Overend T, Barrios J, McCutcheon B, Sidon J. External nasal dilator strips do not affect treadmill performance in subjects wearing mouthguards. J Athl Train. 2000;35(1):60-64.

15. Bourdin M, Sallet P, Dufour AB, Lacour JR. Influence of changes in nasal ventilation on estimated workload during submaximal field running. J Sports Med Phys Fitness. 2002;42(3):295-299.

16. Nespereira AB, Solé AE, Martínez IP, Soriano AR. Tiritas nasales y entrenamiento de la fuerza resistencia en triátlon. Apunts: Educación Física y Deportes. 2004;76:43-47.

17. Thomas DQ, Bowdoin BA, Brown DD, McCaw ST. Nasal strips and mouthpieces do not affect power output during anaerobic exercise. Res Q Exerc Sport. 1998;69(2):201-204.

18. Case S, Redmond T, Currey S, Wachter M, Resh J. The effects of the Breathe Right nasal strip on interval running performance. $J$ Strength Cond Res. 1998;12(1):30-32.

19. Trocchio M, Fisher J, Wimer JW, Parkman AW. Oxygenation and exercise performance-enhancing effects attributed to the breathe-right nasal dilator. J Athl Train. 1995;30(3):211-214.

20. O'Kroy JA, James T, Miller JM, Torok D, Campbell K. Effects of an external nasal dilator on the work of breathing during exercise. Med Sci Sports Exerc. 2001;33(3):454-458.

21. Repovich WE, Roehl MJ, Coelho AJ. Effectiveness of the Breathe Right $^{\mathrm{TM}}$ on $\mathrm{V}_{\mathrm{e}}$ and Rpe in collegiate distance runners. Med Sci Sports Exerc. 1998;30(5):33. Annual Meeting Abstracts.

22. Pinto KMC, Kellen K, Casas RL, Pascoa MRS. Analysis of the influence of the external nasal dilator on the area of the nasal cavity in the rest and on the maximum capacity in the activities that use the oxygen from the air and the heart rate in cycle ergometer. The FIEP Bulletin. 2006;(76):276-279.

23. Nunes VNG, Barbosa DCS, Damasceno WC, et al. External nasal dilator strip does not affect heart rate, oxygen consumption, ventilation or rate of perceived exertion during submaximal exercise. J Exerc Physiol. 2011;14(1):11-19.

24. Tong TK, Fu FH, Chow BC. Effect of nostril dilatation on prolonged all-out intermittent exercise performance. J Sports Med Phys Fitness. 2001;41(2):189-195.

25. Tong TK, Fu FH, Chow BC. Nostril dilatation increases capacity to sustain moderate exercise under nasal breathing condition. $J$ Sports Med Phys Fitness. 2001;41(4):470-478.

26. Chinevere TD, Faria EW, Faria IE. Nasal splinting effects on breathing patterns and cardiorespiratory responses. J Sports Sci. 1999;17(6):443-447.

27. Faria EW, Foster C, Faria IE. Effect of exercise and nasal splinting on static and dynamic measures of nasal airflow. $J$ Sports Sci. 2000;18(4):255-261.

28. Pujol TJ, Langenfeld ME, Hinojosa JR, Iman WH. Effects of an external nasal dilator strip on differentiated ratings of perceived exertion. Percept Mot Skills. 1998;86(3 Pt 2):1153-1154.

29. Deyak JA, Goldsworthy S, Meierhofer D, Bacharach D. Performance and recovery effects of Breathe Right nasal strips during a simulated hockey period. Med Sci Sports Exerc. 1998;30(5):311. Annual Meeting Abstracts.

30. Seto-Poon M, Amis TC, Kirkness JP, Wheatley JR. Nasal dilator strips delay the onset of oral route breathing during exercise. Can J Appl Physiol. 1999;24(6):538-547.

31. Macfarlane DJ, Fong SK. Effects of an external nasal dilator on athletic performance of male adolescents. Can J Appl Physiol. 2004;29(5): 579-589.

32. Wilson RC, Jones PW. A comparison of the visual analogue scale and modified Borg scale for the measurement of dyspnoea during exercise. Clin Sci. 1989;76: 277-282.

33. Dinardi RR, Ibiapina CC, Andrade CR. Evaluation of the effectiveness of the external nasal dilator strip in adolescent athletes: a randomized trial. Int J Pediatr Otorhinolaryngol. 2013;77(9):1500-1505. 
34. Moses AJ. External nasal dilators: a clinical aid for dentists, patients. J Am Dent Assoc. 2001;32:1555-1556.

35. Turnbull GL, Rundell OH, Rayburn WF, Jones RK, Pearman CS. Managing pregnancy-related nocturnal nasal congestion. The external nasal dilator. J Reprod Med. 1996;41(12):897-902.

36. Scharf MB, Berkowitz DV, McDannold MD, Stover R, Brannen DE, Reyna R. Effects of an external nasal dilator on sleep and breathing patterns in newborn infants with and without congestion. $J$ Pediatr. 1996;129(6):804-808.

37. Bahammam AS, Tate R, Manfreda J, Kryger MH. Upper airway resistance syndrome: effect of nasal dilation, sleep stage, and sleep position. Sleep. 1999;22(5):592-598.

38. McLean HA, Urton AM, Driver HS, et al. Effect of treating severe nasal obstruction on the severity of obstructive sleep apnoea. Eur Respir J. 2005;25(3):521-527.

39. Ochi K, Ohashi T. The effects of an external nasal dilator and nasal dimensions in Asians. Otolaryngol Head Neck Surg. 2002;126:160-163.

40. Raudenbush B. Stenting the nasal airway for maximizing inspiratory airflow: internal Max-Air Nose Cones versus external Breathe Right strip. Am J Rhinol Allergy. 2011;25(4):249-251.

41. Roithmann R, Chapnik J, Zamel N, Barreto SM, Cole P. Acoustic rhinometric assessment of the nasal valve. Am J Rhinol. 1997;11(5): 379-385.

42. Høyvoll LR, Lunde K, Li HS, Dahle S, Wentzel-Larsen T, Steinsvåg SK. Effects of an external nasal dilator strip (ENDS) compared to xylometazolin nasal spray. Eur Arch Otorhinolaryngol. 2007;264(11): 1289-1294.

43. Kirkness JP, Wheatley JR, Amis TC. Nasal airflow dynamics: mechanisms and responses associated with an external nasal dilator strip. Eur Respir J. 2000;15(5):929-936.

44. Wong LS, Johnson AT. Decrease of resistance to airflow with nasal strips as measured with the airflow perturbation device. Biomed Eng Online. 2004;22;3(1):38.

45. Gosepath J, Amedee RG, Romantschuck S, Mann WJ. Breathe Right nasal strips and the respiratory disturbance index in sleep related breathing disorders. Am J Rhinol. 1999;13(5):385-389.

46. Latte J, Taverner D. Opening the nasal valve with external dilators reduces congestive symptoms in normal subjects. Am J Rhinol. 2005;19(2):215-219.

47. Liistro G, Rombaux P, Dury M, Pieters T, Aubert G, Rodenstein DO. Effects of Breathe Right on snoring: a polysomnographic study. Respir Med. 1998;92(8):1076-1078.

48. Ulfberg J, Fenton G. Effect of breathe right nasal strip on snoring. Rhinology. 1997;35(2):50-52.

49. Pevernagie D, Hamans E, Van Cauwenberge P, Pauwels R. External nasal dilation reduces snoring in chronic rhinitis patients: a randomized controlled trial. Eur Respir J. 2000;15(6):996-1000.
50. Ng BA, Mamikoglu B, Ahmed MS, Corey JP. The effect of external nasal dilators as measured by acoustic rhinometry. Ear Nose Throat $J$. 1998;77(10):840-844.

51. Scharf MB, Brannen DE, McDannold M. A subjective evaluation of a nasal dilator on sleep and snoring. Ear Nose Throat J. 1994;73: 395-401.

52. Djupesland PG, Skatvedt O, Borgersen AK. Dichotomous physiological effects of nocturnal external nasal dilation in heavy snorers: the answer to a rhinologic controversy? Am J Rhinol. 2001;5(2):95-103.

53. Johns MW. A new method for measuring daytime sleepiness: the Epworth sleepiness scale. Sleep. 1991;4(6):540-545.

54. Sadan O, Shushan S, Eldar I, et al. The effects of an external nasal dilator on labor. Am J Rhinol. 2005;19(2):221-224.

55. Neuenschwander H, Molto A, Bianchi M. External nasal dilator strips (ENDS) may improve breathlessness in cancer patients. Support Care Cancer. 2006;14(4):386-388.

56. Moses AJ, Lieberman M. The effect of external nasal dilators on blood oxygen levels in dental patients. J Am Dent Assoc. 2003;134:97-101.

57. Peltonen LI, Vento SI, Simola M, Malmberg H. Effects of the nasal strip and dilator on nasal breathing: a study with healthy subjects. Rhinology. 2004;42(3):122-125.

58. Gosepath J, Mann WJ, Amedee RG. Effects of the Breathe Right nasal strips on nasal ventilation. Am J Rhinol. 1997;11(5):399-402.

59. Amis TC, Kirkness JP, di Somma E, Wheatley JR. Nasal vestibule wall elasticity: interactions with a nasal dilator strip. J Appl Physiol. 1999;86(5):1638-1643.

60. Lorino AM, Lofaso F, Drogou I, et al. Effects of different mechanical treatments on nasal resistance assessed by rhinometry. Chest. 1998;114(1):166-170.

61. Hornung DE, Chin C, Kurtz DB, Kent PF, Mozell MM. Effect of nasal dilators on perceived odor intensity. Chem Senses. 1997;22(2): $177-180$.

62. Hornung DE, Smith DJ, Kurtz DB, White T, Leopold DA. Effect of nasal dilators on nasal structures, sniffing strategies, and olfactory ability. Rhinology. 2001;39(2):84-87.

63. Seren E. The effect of an adhesive external nasal dilator strip on the inspiratory nasal airflow. Am J Rhinol Allergy. 2010;24(1):e29-e31.

64. Raudenbush B, Meyer B. Effect of nasal dilators on pleasantness, intensity and sampling behaviors of foods in the oral cavity. Rhinology. 2001;39(2):80-83.

65. Nigro CE, Mion O, Mello JF Jr, Voegels RL, Roithmann R. Acoustic rhinometry: impact of external nasal dilator on the two first notches of the rhinogram. Am J Rhinol Allergy. 2011;25(6):247-250.

66. Gerek M, Durmaz A, Aydin U, Birkent H, HidirY, Tosun F. Relationship between nasal valve changes and nasalance of the voice. Otolaryngol Head Neck Surg. 2012;147(1):98-101.
International Journal of General Medicine

\section{Publish your work in this journal}

The International Journal of General Medicine is an international, peer-reviewed open-access journal that focuses on general and internal medicine, pathogenesis, epidemiology, diagnosis, monitoring and treatment protocols. The journal is characterized by the rapid reporting of reviews, original research and clinical studies across all disease areas.
Dovepress

A key focus is the elucidation of disease processes and management protocols resulting in improved outcomes for the patient.The manuscript management system is completely online and includes a very quick and fair peer-review system. Visit http://www.dovepress.com/ testimonials.php to read real quotes from published authors. 